\title{
EFFECT OF COMPRESSION MODALITIES FOR RECOVERY ON WRESTLERS' BIOMARKERS IN ONE DAY TOURNAMEENT
}

\author{
Mohamed S. Ghoraba, 1, A, B, C, E Marwa F. Ghazy2, A, B, D, E \\ 1 Tanta University, Faculty of Physical Education, Department of Combat and Individual Sport, Egypt \\ ${ }^{2}$ Tanta University, Faculty of Physical Education, Department of Sport Health Sciences, Egypt

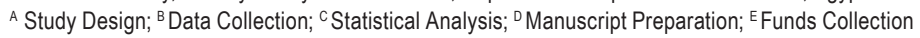 \\ Address for correspondence: \\ Mohamed S. Ghoraba \\ Tanta University, Faculty of Physical Education \\ 31773 Tanta, Seperbay, Seperbay Campus \\ E-mail: m_ghoraba@yahoo.com
}

\begin{abstract}
Ahstract The aim of the study was to investigate the effect of different compression modalities as to recovery enhancement on some biomarkers in wrestlers.

Serum creatinine, lactic acid and glucose level were tested in elite wrestlers before a match-up, 3 minutes post-match up and 19 minutes after applying recovery compression model.

The results showed insignificant differences between pre-post 3-minutes tests among research groups due to sample equality, 3-minutes and 19-minutes post match up tests showed efficacy of compression technique in enhancing recovery in sake of $160 / 20 \mathrm{mmHg}$ compression modality with enhancement percentage of $16.614 \%$ for serum creatinine, $43.214 \%$ for lactic acid and $22.505 \%$ for glucose level.

The compression band with 160/20 mmHg exceeds recovery after match-up.
\end{abstract}

Key Worlds Compression modalities, recovery, wrestling, serum creatinine "SCR", lactic acid "LA", glucose level "GL"

\section{Introduction}

Fatigue has been investigated in different sports to theorize its classification. Mechanical fatigue can be realized as a decline in muscle strength or efficiency, while psychological fatigue states tiredness, perception and low cognitive function. The physiological fatigue occurs in insufficient blood flow to the working tissue and weakening muscle contraction. Fatigue also restrains nervous activation and metabolism; some fatigue may be controlled by passive recovery, but muscular fatigue is complicated because of its extended effect (Allen, Lamb, Westerbland, 2008; Gambetta, 2007; Green, 1997; Locke, Osborne, O'rouke, 2009), especially in the maximal power when measured immediately after the fatiguing performance (Hunter, Critchlow, Shin, Enoka, 2004; Lévénez, Kotzamanidis, Carpentier, Duchateau, 2005; McNeil, Murray, Rice, 2006). Scientists claim lactic acid production as prior factor of fatigue, resulting of severe exercise, but there is a growing interest of studying other metabolic 
byproducts causing fatigue (Brooks, 2001; Kass, Carpenter, 2009). The impact of fatigue on athlete's achievement actuates scientists to monitor training loads, recovery duration and modality (Allen et al., 2008; Thorpe, Atkinson, Drust, Gregson, 2017).

Proper recovery aims at restoration of physiological and psychological excellence, so that the athlete can compete or continue training at optimal level depending on the exercise's nature.

Compression techniques of recovery vary in application and effect. Ischemic preconditioning (IPC) consists of repeated cycles of vascular occlusion with high pressure cuff applied on upper or lower limbs, followed by reperfusion in which pressure in the cuff is gradually released. IPC is known to improve vasodilation, oxygen utilization muscle function and to enhance exercise performance (Dalleck, 2018).

Compression garments are one of the recovery applications that use a graduated compression on the limbs from proximal to distal. Compression pressure of a garment reduces the intramuscular space prone to swelling and promotes stable alignment of muscle fibers (Bochmann et al., 2005; Kraemer et al., 2010).

IPC improves muscle blood flow, oxygen delivery and may contribute to an increased removal of lactate including the potential up regulation of intra- and extracellular lactate shuttles during exercise (Brooks, 2000; Hashimoto, Brooks, 2008; Riksen, Smits, Rongen, 2004).

Periodic cycles of ischemic compression followed by gradual reperfusion, enhance molecular, vascular adaptations and muscular blood flow (Berger, Macholz, Mairbaurl, Bartsch, 2015; Tapuria et al., 2008).

Compression for recovery of post-exercise fatigue may cease inflammatory responses, reduce $v$ delayed onset muscle soreness and accelerates recovery process period (Duffield, Cannon, King, 2010; Pruscino, 2013).

High intensity exercise, especially eccentric muscle contraction, results in high circulating creatinine (Koch, Pereira, Machado, 2014), which is related to the athletes' muscle size, fiber type, and exercising duration (Gleeson, Maughan, 2013).

Whole blood or plasma creatinine and estimated glomerular filtration rate are particularly increased in strength sports, while creatinine kinase (CK) may be elevated during acute changes in training load. However, regarding the inter- and intraindividual variations within the same or different seasons, the effect of exercise on biomarker concentrations, and the lack of reference values, little progress has been made towards the integration of these tools in sports practice and the discrimination among health training, overtraining and fatigue (Banfi, Colombini, Lombardi, Lubkowska, 2012; Fragala, Bi, Chaump, Kaufman, Kroll, 2017; Meeusen et al., 2013).

Wrestling is a part of poly-structural acyclic sports. Wrestling matches occur in the zone of maximal and submaximal load. The energetics of wrestling is very complex, anaerobic glycolytic or lactic pathways prevail during a fight, in order to perform sudden, explosive throws or lifting (Karninčić, Gamulin, Nurkić, 2013).

Hematological biomarkers have been proven valid for quantifying and monitoring training load throughout a training period (Djaoui, Haddad, Chamari, Dellal, 2017).

From above reading one can state that varieties of compression modalities had been investigated in regard to their effect in enhancing recovery, eliminating biomarkers of fatigue as serum creatinine, lactic acid and restoring glucose level. However, there has never been a certain procedure in estimating pressure or location of the compression, so the researchers aimed to establish a new compression modality and investigate its effect on serum creatinine, lactic acid clearance, and glucose level. 


\section{Materials and Methods}

Experimental method had been used to investigate the effect of three compression modalities on lactic acid clearance, serum creatinine and glucose level in blood using pre- and post-test.

Sample: Twenty four elite wresters (aged 18-23 and weighted 82-87) from registered Egyptian federation players participated in this study; the sample was divided into 4 groups (control; experimental - Exp1; experimental - Exp2; experimental - Exp3). Each group consisted of 6 players; 12 players intentionally played in each official weigh. The data in Table 1 describe homogeneity of the sample.

Table 1. Means, standard deviation and variance of sample groups in research variables

\begin{tabular}{|c|c|c|c|c|c|c|c|c|c|c|c|c|c|}
\hline \multirow{2}{*}{ Variables } & \multicolumn{3}{|c|}{ Control } & \multicolumn{3}{|c|}{ Exp1 } & \multicolumn{3}{|c|}{ Exp2 } & \multicolumn{3}{|c|}{ Exp3 } & \multirow{2}{*}{$\begin{array}{c}\text { Hartly } \\
\text { test }\end{array}$} \\
\hline & $M$ & $\pm S D$ & v & $M$ & $\pm S D$ & v & $M$ & $\pm S D$ & v & $M$ & $\pm S D$ & v & \\
\hline SCR & 1.080 & 1.175 & 0.044 & 1.130 & 1.115 & 0.015 & 1.093 & 1.095 & 0.021 & 1.092 & 1.100 & 0.032 & 2.976 \\
\hline LA & 2.500 & 2.500 & 0.200 & 2.483 & 2.500 & 0.222 & 2.633 & 2.700 & 0.127 & 2.617 & 2.700 & 0.138 & 1.750 \\
\hline $\mathrm{GL}$ & 128.500 & 128.500 & 19.500 & 127.333 & 128.000 & 11.467 & 127.167 & 126.500 & 47.367 & 128.833 & 129.000 & 25.367 & 4.131 \\
\hline
\end{tabular}

Note: Homogeneity of research groups, where significance between $4.5 \mathrm{~F}$ (Freedom degrees) at $0.05=13.7$. Variance differences were insignificant according to Hartly test.

Measurements: Venous blood samples were taken from players before participating in the customized match as in officially organized matches. The measurements were serum creatinine, lactic acid and glucose. Samples preserved in vacutainers till were sent to medical lab to be analyzed.

Serum creatinine "SCR": Serum creatinine is one of health biomarkers which states the athlete's responses to physical performance, especially in exhaustive performance that produces high loss of hydro electrolytes. High training workload and psychophysical stress from competitions may modify their homoeostasis, inducing apparently pathological biochemical and hematological values. Therefore, the definition of the behavior of creatinine (Banfi, Del Fabbro, 2006; Banfi, Del Fabbro, 2006), where exercise will acutely change serum creatinine level depending on the severity and duration of the exercise, as well as on the age of athletes (Banfi, Del Fabbro, Lippi, 2009).

Serum creatinine concentrations were higher than those measured in age matched sedentary subjects. This finding may be linked to the average higher muscle mass of athletes, because total muscle mass is the most important determinant of the creatinine pool size and of creatinine production (Perrone, Madias, Levey, 1992). Exercise-induced changes in creatinine levels are transient and promptly normalize during the recovery (Banfi, Del Fabbro, Lippi, 2009).

Lactic acid "LA": Lactic acid is an important marker of fatigue (Hübner-Woźniak, Kosmol, Lutoslawska, Bem, 2004; Hübner-Woźniak, Lutoslawska, Kosmol, Zuziak, 2006; Kraemer et al., 2001), blood lactate varies directly after exercise and following exercise depending on the time at which it was sampled. Depending on the mode of exercise and sample site, extracted blood borne parameters could be altered, yet recovery of lactate changes up to twentyfive minutes post exercise. Training has also proven to increase the rate at which lactate is removed after aerobic and anaerobic exercise (Karninčić, Tocilj, Uljević, Erceg, 2009; Kass, Carpenter, 2009).

Glucose "GL": Physical training enhances insulin-stimulated glucose disposal in proportion to the improvement in physical fitness (Mikines, Sonne, Farrel, Tronier, Galbo, 1988; Soman, Koivisto, Deibert, Felig, DeFronzo, 1997). 
Physical training is known to improve insulin sensitivity, both immediately post-exercise and through multiple long-term adaptations in glucose transport and metabolism (Costill, Hargreaves, 1990).

However, in contrast, strenuous exercise is known to increase circulating concentrations of catecholamines, such as adrenalin and noradrenaline, to near pathological levels, resulting in hyperglycemia and hyperinsulinemia post-intense exercise (Marliss, Vranic, 2002; Rehrer, Brouns, Beckers, 1992).

Lactic acid, serum creatinine and glucose level were investigated among several sports players, where little is known about their profile during a wrestling competition. Venues blood samples were collected, maintained in a vacutainer and handled in ice box till to medical lab of Tanta. Samples collected from arm vein where closer to active muscle in wrestling arm performances, referring to previous study (Comeau, Lawson, Graves, Church, Adams, 2011) that declared sampling blood lactate from sites that are not close to the working muscle could result in inaccurate blood lactate level due to the pooling of lactate in areas of inactive muscles.

\section{Main protocol}

Pilot study was carried out on 2 wrestlers to investigate the utility of the equipment and assistants needed, where the researchers decided to have two lab experts to ensure the blood collecting process speed.

The main experiment was carried out in two days. Customized match conditions were as following: morning breakfast was 1 hour before the experiment and consisted of $200 \mathrm{ml}$ of orange juice, two bananas and a slice of cake. No further food was supplied tell the end of the 19-minutes post-match test. 3 blood samples of $3 \mathrm{~cm}$ (first one in the morning before players wormed up, second one after 3-minutes post-match and third one 19 minutes post-match; with and without recovery modality). The blood samples collecting is presented in Figure 1.

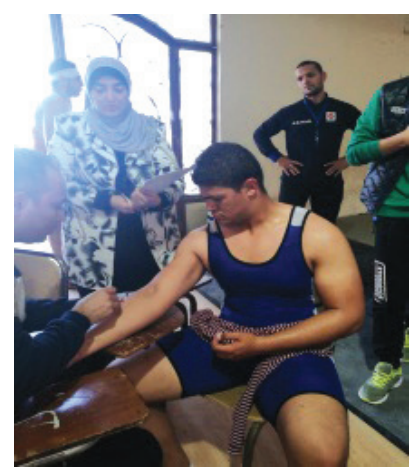

Figure 1. Blood samples collecting

Players performed in wrestling matches of two rounds, 3 minutes each; intermittent rest of 30 seconds with confirmed condition manipulation (eliminating the shoulder touch down - OUTO touch), neglecting the score superiority (super URTY). Matching underwent the whole timing of 6 minutes with 30-second intermittent rest. United World Wrestling (UWW) organized the first-round matches (3-4 matches) with 20 minutes intermitted rest. Every two groups wrestled each other randomly according to weight (Figure 2) documentary of wrestling match. 


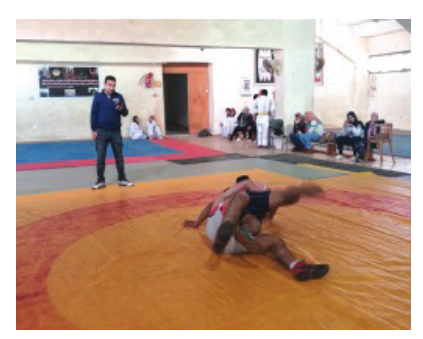

Figure 2. Documentary of wrestling match

After 3-minutes post-match, players were classified into four groups. The players from the control group did not apply any recovery method (passive recovery).

Group Exp1 applied intermittent compression band (inflator cuff) for 14 minutes with interval 2-minute compression, then 2-minute release. The compression was $160 \mathrm{~mm} \mathrm{Hg}$ (mercuric pressure), with gradual release up to $20 \mathrm{~mm} \mathrm{Hg}$. Figure 3 represents the athletes applying inflatable cuff with 160/20 mm Hg.

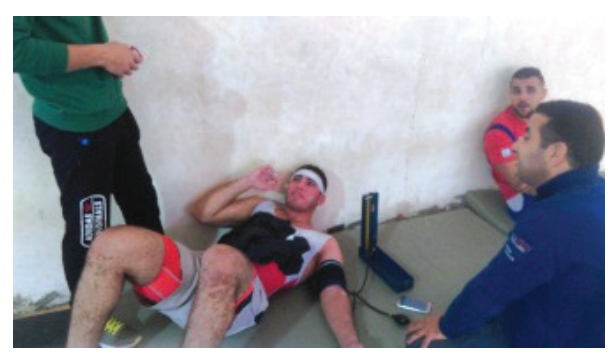

Figure 3. Athletes applying inflatable cuff

Previous studies varied in their compression pressure, compression sites, upper limb or lower limb, single or duple site occlusion and compression tactics. I. San Millán et al. (2013) used MMC devise on feet with intervals of pressure and gradual release. A. Kraus et al. (2015) used an automated inflatable cuff (E20 Rapid Cuff Inflator) with four cycles of 5 -minute occlusion, each followed by 5 -minute reperfusion.

Group Exp2 applied intermittent compression band (inflator cuff) for 14 minutes with interval 2-minute compression, then 2-minute release. The compression was $120 \mathrm{~mm} \mathrm{Hg}$ (mercuric pressure), with gradual release up to $20 \mathrm{~mm} \mathrm{Hg}$.

Group Exp3 applied IPC device, arm cuff for 15 minutes. Figure 4 represents an athlete applying IPC cuff. 


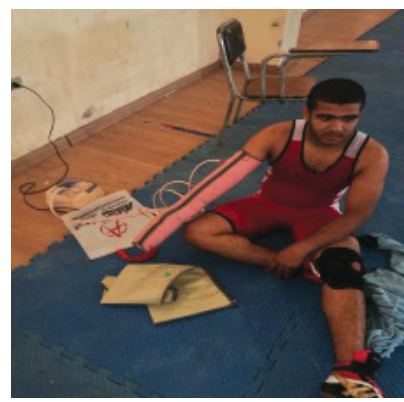

Figure 4. An athlete applying IPC cuff

A previous study (Hanson, Stetter, Thomas, 2013) emphasized that using IPC for recovering was faster especially after a multitude of competition (Jones, 2016). There was used graduated low-pressure 20:15:10 mm Hg IPC use and graduated high-pressure 70:65:60 mm Hg IPC. T. Waller et al. (2006) utilized the IPC as a recovery modality with graduated low-pressure $(20 \mathrm{~mm} \mathrm{Hg})$ IPC use, and graduated high-pressure $(70 \mathrm{~mm} \mathrm{Hg})$ IPC. M. Winke and S.H. Williamson (2018) also demonstrated intermittent pressure release with $100 \mathrm{~mm} \mathrm{Hg}$.

\section{Statistical procedures}

Statistical analyses were performed using SPSS software. All data are reported as means; SD - "standard deviation", ANOVA - "analysis of variance", LSD - "least significant differences" and enhancement percentage Hartly test were assumed at $p<0.05$. Experimental method was that of four groups using 1 pre-test and 2 post-test.

\section{Results}

Analytic treatment of research data resulted in differences among the four research groups. Tables 2 and 3 represent the means, LSD and enhancement percentage of the pre-tests of the research variables (Serum Creatinine - SCR, Lactic acid - LA and Glucose - GL) of the four research groups (Control - cont., Experimental 1 - Exp1, Experimental 2 - Exp2 and Experimental 3 - Exp3).

Tahle 2. Means, LSD and enhancement percentage of the pre-tests of the four research groups

\begin{tabular}{|c|c|c|c|c|c|c|c|c|c|c|c|c|c|}
\hline \multirow{2}{*}{ No. } & \multirow{2}{*}{ Variables } & \multicolumn{3}{|c|}{ Cont. } & \multicolumn{3}{|c|}{ Exp1 } & \multicolumn{3}{|c|}{ Exp2 } & \multicolumn{3}{|c|}{ Exp3 } \\
\hline & & SCR & LA & GL & SCR & LA & GL & SCR & LA & GL & SCR & LA & GL \\
\hline 1 & 2 & 3 & 4 & 5 & 6 & 7 & 8 & 9 & 10 & 11 & 12 & 13 & 14 \\
\hline \multirow{3}{*}{$\begin{array}{l}\stackrel{\infty}{\mathbb{D}} \\
\stackrel{\mathbb{\infty}}{\Sigma}\end{array}$} & pre & 1.080 & 2.500 & 128.500 & 1.130 & 2.483 & 127.333 & 1.093 & 2.633 & 127.167 & 1.092 & 2.617 & 128.833 \\
\hline & post 3-minutes & 1.232 & 20.200 & 72.000 & 1.298 & 20.433 & 74.500 & 1.292 & 20.017 & 72.500 & 1.307 & 20.400 & 73.833 \\
\hline & post 19-minutes & 1.245 & 15.350 & 85.167 & 1.053 & 8.717 & 104.333 & 1.210 & 11.817 & 91.333 & 1.228 & 12.150 & 90.167 \\
\hline \multicolumn{2}{|l|}{ LSD } & 0.216 & 1.899 & 6.642 & 0.127 & 1.039 & 4.776 & 0.129 & 1.863 & 5.607 & 0.170 & 2.053 & 4.905 \\
\hline \multicolumn{2}{|l|}{$\mathrm{F}$} & 1.6329 & $210.573^{*}$ & $179.842^{*}$ & $8.8672^{*}$ & $697.951^{*}$ & $279.245^{*}$ & $5.193^{*}$ & $197.685^{*}$ & $222.698^{*}$ & $3.712^{*}$ & $170.592^{*}$ & $213.012^{*}$ \\
\hline \multicolumn{2}{|c|}{$P$ value } & 0.112 & 0.000 & 0.000 & 0.000 & 0.000 & 0.000 & 0.000 & 0.000 & 0.000 & 0.000 & 0.000 & 0.000 \\
\hline \multicolumn{2}{|c|}{$\begin{array}{l}\text { Enhancement } \\
\text { percentage }\end{array}$} & pre & $\begin{array}{l}\text { Post } \\
3 \mathrm{~min}\end{array}$ & $\begin{array}{c}\text { Post } \\
19 \mathrm{~min}\end{array}$ & pre & $\begin{array}{l}\text { Post } \\
3 \mathrm{~min}\end{array}$ & $\begin{array}{c}\text { Post } \\
19 \mathrm{~min}\end{array}$ & pre & $\begin{array}{l}\text { Post } \\
3 \mathrm{~min}\end{array}$ & $\begin{array}{c}\text { Post } \\
19 \text { min }\end{array}$ & pre & $\begin{array}{l}\text { Post } \\
3 \mathrm{~min}\end{array}$ & $\begin{array}{l}\text { Post } \\
19 \mathrm{~min}\end{array}$ \\
\hline
\end{tabular}




\begin{tabular}{|c|c|c|c|c|c|c|c|c|c|c|c|c|c|}
\hline 1 & 2 & 3 & 4 & 5 & 6 & 7 & 8 & 9 & 10 & 11 & 12 & 13 & 14 \\
\hline \multirow{3}{*}{ 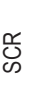 } & pre & & 14.043 & 15.278 & & 14.897 & 6.814 & & 18.140 & 10.671 & & 19.695 & 12.519 \\
\hline & post 3-minutes & & & 1.083 & & & 18.896 & & & 6.323 & & & 5.995 \\
\hline & post 19-minute & & & & & & & & & & & & \\
\hline \multirow{3}{*}{ 苂 } & pre & & 708.000 & 514.000 & & 722.819 & 251.007 & & 660.127 & 348.734 & & 679.618 & 364.331 \\
\hline & post 3-minute & & & 24.010 & & & 57.341 & & & 40.966 & & & 40.441 \\
\hline & post 19-minute & & & & & & & & & & & & \\
\hline \multirow{3}{*}{ 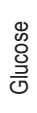 } & pre & & 43.969 & 33.722 & & 41.492 & 18.063 & & 42.988 & 28.178 & & 42.691 & 30.013 \\
\hline & post 3-minute & & & 18.287 & & & 40.045 & & & 25.977 & & & 22.122 \\
\hline & post 19-minute & & & & & & & & & & & & \\
\hline
\end{tabular}

${ }^{*} p$ value $<0.05, F$ value at 2.15 , significance $0.05=3.68$.

Tahle 3. ANOVA, LSD and enhancement percentage of the post-tests among research four groups

\begin{tabular}{|c|c|c|c|c|c|c|c|c|c|c|c|c|c|}
\hline \multirow{2}{*}{ Variables } & \multirow{2}{*}{ Groups } & \multirow{2}{*}{ Means } & \multicolumn{4}{|c|}{ Enhancement perc. } & \multicolumn{4}{|c|}{$M D$} & \multirow{2}{*}{ LSD } & \multirow{2}{*}{$\mathrm{F}$} & \multirow{2}{*}{$\mathrm{p}$ value } \\
\hline & & & Cont. & Exp1 & Exp2 & Exp3 & Cont. & Exp1 & Exp2 & Exp3 & & & \\
\hline \multirow{4}{*}{ SCR } & Cont. & 1.245 & & 15.395 & 2.811 & 1.339 & & $0.192^{*} \uparrow$ & 0.035 & 0.017 & \multirow{4}{*}{0.114} & \multirow{4}{*}{$5.477^{\star}$} & \\
\hline & Exp1 & 1.053 & & & 14.873 & 16.614 & & & $0.157^{*} \rightarrow$ & $0.175^{*} \rightarrow$ & & & 0.001 \\
\hline & Exp2 & 1.210 & & & & 1.515 & & & & 0.018 & & & \\
\hline & Exp3 & 1.228 & & & & & & & & & & & \\
\hline \multirow{4}{*}{ LA } & Cont. & 15.350 & & 43.214 & 23.018 & 20.847 & & 6.633 & $3.533^{*} \uparrow$ & $3.200^{*} \uparrow$ & \multirow{4}{*}{0.580} & \multirow{4}{*}{$189.888^{*}$} & \\
\hline & Exp1 & 8.717 & & & 35.564 & 39.388 & & & $3.100^{*} \rightarrow$ & $3.433^{*} \rightarrow$ & & & 0.00 \\
\hline & Exp2 & 11.817 & & & & 2.821 & & & & 0.333 & & & \\
\hline & Exp3 & 12.150 & & & & & & & & & & & \\
\hline \multirow{4}{*}{ GL } & Cont. & 85.167 & & 22.505 & 7.241 & 5.871 & & 19.167 & $6.167^{\star} \uparrow$ & $5.000^{*} \uparrow$ & \multirow{4}{*}{3.886} & \multirow{4}{*}{$38.469^{*}$} & \\
\hline & Exp1 & 104.333 & & & 12.460 & 13.578 & & & $13.000^{*} \rightarrow$ & $14.167^{*} \rightarrow$ & & & 0.00 \\
\hline & Exp2 & 91.333 & & & & 1.277 & & & & 1.167 & & & \\
\hline & Exp3 & 90.167 & & & & & & & & & & & \\
\hline
\end{tabular}

${ }^{*} p$ value $<0.05, F$ value at 3.20 , significance $0.05=3.01$. Horizontal arrows are indicators of significance, vertical arrows are the highest significance; $\rightarrow-$ highest significance.

\section{Discussion}

Recent research aimed at investigating different compression modalities on wrestlers' recovery after customized wrestling match. Different compression modalities showed significant differences towards enhancement of postperformance recovery, varied by the recovery procedure. Pre matching tests showed no differences owing to the homogeneity of the wrestlers' performance level and BMI. 3-minute post-match tests showed little differences with insignificance, due to reason. 19-minute post-match tests taken after application of different recovery modalities, showed varied readings with significant differences between experiment groups and control group.

Serum creatinine "SCR": The concentration of serum creatinine is a reliable indicator of renal function in medicine research (Perrone et al., 1992). Serum creatinine positively responses to physical exercise, and vary according to sample age, exercise intensity and duration (Banfi et al., 2009). 
In recent study, serum creatinine resulted in dramatic increase in 3-minute post-match test, ranging $1.23-1.30 \mathrm{mg} / \mathrm{dL}$. That may indicate subclinical muscle disease, where training loads may evidence through the onset of profound fatigue as in the study of P. Brancaccio et al. (2007).

Our findings matched the study of N. Gill, C. Beaven and C. Cook (2005) and I. Papassotiriou and A. Nifli (2018) who emphasized higher excretion of serum creatinine in $70 \%$ of the athletes according to athlete's body mass, especially in wrestlers, while athletes with lower creatinine concentrations presumed albumin abnormality.

M.S. Fragala et al. (2017) proved that strength exercise was associated with higher levels of creatinine, where physical performance compels athlete's muscles to process high amounts of creatine which produce higher levels of serum creatinine.

In the 19-minute post-match creatinine test, after applying 3 different recovery modality, the results among groups showed insignificant differences between cont. and Exp3 groups, which declares that compression modality of (IPC) was less influenced than passive recovery. Significant differences between Exp1, Exp2 and cont. groups differed according to the recovery modality, with recovery of creatinine clearance in favor of the Exp1 with mean $1.03 \mathrm{mg} / \mathrm{dL}$, showing the superiority of compression modality (160/20 mm Hg). Exp2 with 140/20 mm Hg modality showed significant difference to cont. group and to Exp1 in sake of the latter, where enhancement percentages were as follows: $16.614 \%, 15.395 \%$ and $14.873 \%$ between Exp1, Exp2 and Exp3 respectively.

Creatinine clearance after match-up in wrestling is essential for wrestlers to continue the match-up in preparation phase or in finals, using recovery modality to shorten the recovery period.

Our findings matched the studies of P. Brancaccio et al. (2007), K.E. Fallon, G. Sivyer, K. Sivyer and A. Dare (1999), T. Hortobagyi and T. Denhan (1989) and I. Papassotiriou and A. Nifli (2018) that resting creatinine levels are higher in athletes, especially wrestlers.

Creatinine clearance induced by using compression modality, which was previously tested in studies of J. Chase (2017), A. Comerota and F. Aziz (2009), P. Deschênes, D. Joanisse and F. Billaut (2017), T. Lopes et al. (2018) and R. Thorpe et al. (2017), emphasizing the validity of compression modalities in enhancing limb vasculature, blood circulation, oxidation and post exercise recovery.

Lactic acid "LA": Lactate is the product of the anaerobic breakdown of glucose in tissues. While earlier research demonstrated that lactate was a waste product and a cause of acidosis, new findings have shown that lactate not only does not cause acidosis (Robergs, Ghiasvand, Parker, 2004) but it is also a very useful carbohydrate in times of increased energy demand (Miller et al., 2002). Competitive fight particularly depends on the capacity of maximum mobilization of anaerobic lactic energy (Sybil, 2018). The anaerobic system provides the short, quick bursts of maximal power during the match while the aerobic system contributes to the wrestler's ability to sustain effort for the duration of the match (Callan et al., 2000).

Pre match-up lactic acid test was normal range for all research groups with range of "1.9-3.0" mmol'L. Recent results matched the studies of W.J. Kraemer et al. (2001) and K. Mahdi (2007), where resting lactate concentrations before warming up ranged $1.7 \mathrm{mmol} \cdot \mathrm{L}-1$ to $2.6 \mathrm{mmol} \cdot \mathrm{L}-1$.

3-minute post match-up lactate test was raised for all research groups, due to the anaerobic nature of wrestling match performance. Readings differences were insignificant among groups according to the likelihood of training experience, the readings ranged "20.017-20.433 mmol'L", matching the study of H. Karninčić et al. (2009), A.C. Utter, H.S. O'Bryant, G.G. Haff and G.A. Trone (2002), where post-match test ranged "17.1 to $20.0 \mathrm{mmol} \cdot \mathrm{L}$ ". 
19-minute post match-up, lactic acid test, varied in the four research groups with minimal insignificant change in cont. group, where passive recovery did not record lactate clearance, which matches the study of M. Jemni, W. Sands, F. Friemel and P. Delamarche (2003).

Significant differences were found among the experimental groups. The compression modalities showed remarkable attitude in lactate recovery with enhancement percentage of $(43.214,39.388,35.564)$ between Exp1, Exp2 and Exp3, respectively. The highest enhancement was in sake of Exp1 with mean of $8.717 \mathrm{mmol} \cdot \mathrm{L}$, emphasizing on the role of intermittent compression pressure in lactate recovery. Our findings matched the studies of S. Baker and N. King (1991), I. Barbas et al. (2011), E. Hanson et al. (2013) and L. Sharma and S. Verma (2017).

Glucose level "GL": Glucose is a master nutrient of body organs, especially the organs of the nervous system. Insulin and glucagon hormones are the moderators of blood glucose "hyperglycemic and hypoglycemic actions" to normal range in order to keep the body systems out of danger (Marshall, 2012).

3-minute post match-up glucose test recorded high reduction in all research groups, due to the high anaerobic exertion of wrestling match performance. Readings differences were insignificant among groups as the likelihood of training experience, readings ranged "72-74.5mg/dl", where reductions in blood glucose levels have been associated with fatigue matching the studies of P. Abernethy and B. Eden (1992), L.B. Borghouts and H.A. Keizer (2000), D.L. Costill and M. Hargreaves (1990) and M. Goodwin (2010).

19-minute post match-up glucose test recorded high increase in glucose level, matching the study of L. Hermansen, E.D. Pruett, J.B. Osnes and F.A. Giere (1970), which emphasized the great increase in glucose level responding to maximal exercise performance. That increase in blood glucose was deduced in the study of R.H. Coker and M. Kjaer (2005) to be an immediate release of glucose from the liver.

Glucose increase varied in the four research groups enhancement percentage $(22.50,13.578,12.460)$ between Exp1, Exp2 and Exp3, respectively, with high significance in sake of Exp1 with mean $104.333 \mathrm{mg} / \mathrm{dl}$, showing the efficacy of the compression modalities in increasing the muscle blood pooling, matching the studies of M. Goodwin (2010), Z.A. Khayat, N. Patel and A. Klip (2002) and E.A. Richter, W. Derave and J.F. Wojtaszewski (2001) which stated that exercise and hypoxia (resembled in occlusion the procedure in the recent study) induce glucose increase.

Exhaustive bout of wrestling performance represented in recent customized match and hyperemic effect of occlusion- perfusion; recovery modality coincided with the previous finding of J.D. Fluckey et al. (1994) and J. Henriksson (1995), where the reduction in muscle glycogen was an important factor of increasing insulin sensitivity in the post exercise. P. Adams (2015) declared that the high increase in blood glucose lasted up to 1 hour post exercise, leading to Plasma insulin levels rise, correcting the glucose level and restoring muscle glycogen.

The recovery modalities applied in recent study proved their effectiveness in recovery improvement, especially with the dietary restriction condition. The utilization of these different modalities differs by the compression pressure level and the technique of inflation-deflation sequence. The idea of these modalities depends on manipulating blood flow speed and volume, flushing out muscles fatigue products such as lactic acid, which enhance recovery, especially in wrestling matches where multiple performances were exerted. These kinds of compression modalities had been used in blood flow restriction "BFR" training technique, which involves manipulating blood flow, increasing anaerobic function of muscles and enhancing rehabilitation, as in the studies of M. Ghoraba, M. Ghazy and M. El Tomey (2017), L. Hughes, B. Paton, B. Rosenblatt, C. Gissane and S.D. Patterson (2017), A. Kraus et al. 
(2015), C.J. McNeil, M.D. Allen, E. Olympico, J.K. Shoemaker and C.L. Rice (2015) and J. Slysz, J. Stultz and J.F. Burr (2016).

\section{Conclusions}

Compression modalities used in post exercise recovery with different pressure level and technique, as used in this study, showed superiority of high pressure with $160-20 \mathrm{~mm} \mathrm{Hg}$, which accelerated recovery time due to its hyperemic effect of the perfusion. This technique should be used in regard to the athletes' muscularity and blood pressure "systolic and diastolic numbers" with high concern to nerves safety. M.E. Tschakovsky et al. (2004) regarded that peripheral nervous system likely played a role in vasodilation along with compression effect of increasing oxygenation. However, N. Labropoulos, J. Cunningham, S.S. Kang, M.A. Mansour and W.H. Baker (2010) emphasized that higher pressure produced greater increase in blood flow as well as quicker acceleration of blood flow, there is not a fixed value for compression level so far and it is still a matter of research.

\section{References}

Abernethy, P., Eden, B. (1992). Changes in blood glucose levels during a 1005-km running race: a case study. Br J Sport Med, 26 (1), $66-68$.

Adams, P. (2015). The impact of brief high-intensity exercise on blood glucose levels. Diabetes, Metabolic Syndrome and Obesity: Targets and Therapy, 6, 113-122.

Allen, D., Lamb, G., Westerbland, H. (2008). Skeletal muscle fatigue: cellular mechanisms. Physiological Reviews, 88, $287-332$.

Baker, S., King, N. (1991). Lactic acid recovery profiles following exhaustive arm exercise on a canoeing ergometer. Br J Sport Med., $25(3), 165-167$.

Banfi, G., Colombini, A., Lombardi, G., Lubkowska, A. (2012). Metabolic markers in sports medicine. Adv Clin Chem, 56, 1-54.

Banfi, G., Del Fabbro, M. (2006). Relation between serum creatinine and body mass index in elite athletes of different sport disciplines. J Sports Med, 40, 675-678.

Banfi, G., Del Fabbro, M. (2006). Serum creatinine values in elite athletes competing in different sports: comparison with sedentary people. Clin Chem, 52, 330-331.

Banfi, G., Del Fabbro, M., Lippi, G. (2009). Serum Creatinine Concentration and Creatinine-Based Estimation of Glomerular Filtration Rate in Athletes. Sports Med, 39 (4), 331-337.

Barbas, I., Fatouros, I., Douroudos, I., Chatzinikolaou, A., Michailidis, Y., Draganidis, D., Jamurtas, A., Nikolaidis, D., Parotsidis, C., Theodorou, A., Katrabasas, I., Margonis, K., Papassotiriou, I., Taxildaris, K. (2011). Physiological and performance adaptations of elite Greco Roman wrestlers during a one-day tournament. Eur J Appl Physiol, 111, 1421-1436.

Berger, M., Macholz, F., Mairbaur, H., Bartsch, P. (2015). Remote ischemic preconditioning for prevention of high-altitude diseases: fact or fiction. J. Appl. Physiol, 119 (10), 1143-1151.

Bochmann, R.P., Seibel, W., Haase, E., Hietschold, V., Rodel, H., Deussen, A. (2005). External compression increases forearm perfusion. J. Appl. Physiol., 99, 2337-2344.

Borghouts, L.B., Keizer, H.A. (2000). Exercise and insulin sensitivity: a review. Int J Sports Med., 21 (1), 1-12.

Brancaccio, P., Maffulli, N., Limongelli, F. (2007). Creatine kinase monitoring in sport medicine. British Medical Bulletin, 81, 82, 209-230.

Brooks, G. (2001). Lactate doesn't necessarily cause fatigue. Journal of Physiology, 536 (1), 161-166.

Brooks, G. (2000). Intra and extra cellular lactate shuttles. Med Sci Sports Exerc., 32 (4), 790-799.

Callan, S.D., Brunner, D.M., Devolve, K.L., Mulligan, S.E., Hesson, J., Wilber, R.L., Kearney, J.T. (2000). Physiological profiles of elite freestyle wrestlers. Journal of Strength and Condition Research, 14, 162-169.

Chase, J. (2017). The Impact of a Single Intermittent Pneumatic Compression Bout on Performance, Inflammatory Markers, and Myoglobin in Football Athletes. Master of Science, University of Manitoba.

Coker, R.H., Kjaer, M. (2005). Gluco regulation during exercise: the role of the neuroendocrine system. Sports Med, 35 (7), $575-83$. 
Comeau, M., Lawson, P., Graves, M., Church, J., Adams, T. (2011). Visualization of the passive sink phenomenon in non-exercising muscle using 2 sampling sites: consequences for assessment and training. Journal of Strength and Conditioning Research, 25 (10), 2926-2930.

Comerota, A., Aziz, F. (2009). The case for intermittent pneumatic compression. Journal of Lymphoedema, 4 (2), 57-64.

Costill, D.L., Hargreaves, M. (1990). Carbohydrate nutrition and fatigue in Sport and Exercise. Sport Medicine, 13, 86-92.

Dalleck, L.C. (2018). The Science of Post-Exercise Recovery. American Council on Exercise ACE.

Deschênes, P., Joanisse, D., Billaut F. (2017). Ischemic preconditioning increases muscle perfusion, oxygen uptake, and force in strength-trained athletes. Appl. Physiol. Nutr. Metab., 41, 938-944.

Djaoui, L., Haddad, M., Chamari, K., Dellal, A. (2017). Monitoring training load and fatigue in soccer players with physiological markers. Physiol Behav, 181, 86-94.

Duffield, R., Cannon, J., King M. (2010). The effects of compression garments on recovery of muscle performance following highintensity sprint and plyometric exercise. J Sci Med Sport, 12, 136-140.

Fallon, K.E., Sivyer, G., Sivyer, K., Dare, A. (1999). The biochemistry of runners in a 1600 km ultramarathon. Br J Sports Med, 33, 264-269.

Fluckey, J.D., Hickey, M.S., Brambrink, J.K., Hart, K.K., Alexander, K., Craig, B.W. (1994). Effects of resistance exercise on glucose tolerance in normal and glucose-intolerant subjects. Appl Physiol, 77, 1087-1092.

Fragala, M.S., Bi, C., Chaump, M., Kaufman, H.W., Kroll, M.H. (2017). Associations of aerobic and strength exercise with clinical laboratory test values. PLoS One, 12, e0180840.

Gambetta, V. (2007). Athletic development-the art \& science of functional sports conditioning. Champaign, IL: Human Kinetics.

Ghoraba, M., Ghazy, M., El Tomey, M. (2017). Effect of exercise program with blood flow restriction on upper limb vasculature and performance in wrestlers. IJSSA, 2, 298-327.

Gill, N., Beaven, C., Cook, C. (2005). Effectiveness of post-match recovery strategies in rugby players. British Journal of Sports Medicine, 40, 260-263.

Gleeson, M., Maughan, R.J. (2013). Biochemistry of exercise. The Encyclopaedia of Sports Medicine: An IOC Medical Commission Publication. Chichester: John Wiley \& Sons Ltd, pp. 36-58.

Goodwin, M. (2010). Blood Glucose Regulation during Prolonged, Submaximal Continuous Exercise: A Guide for Clinicians. Journal of Diabetes Science and Technology, 4 (3), 694-705.

Green, H.J. (1997). Mechanisms of muscle fatigue in intense exercise. Journal of Sports Sciences, 15 (3), 247-256.

Hanson, E., Stetter, K., Thomas, A. (2013). An Intermittent Pneumatic Compression Device Reduces Blood Lactate Concentrations More Effectively Than Passive Recovery after Wingate Testing. J Athl Enhanc, 02, 1-4.

Hashimoto, T., Brooks, G.A. (2008). Mitochondrial lactate oxidation complex and an adaptive role for lactate production. Med Sci Sports Exer, 40 (3), 486-94.

Henriksson, J. (1995). Influence of exercise on insulin sensitivity. Journal of Cardiovascular Risk, 2, 303-309.

Hermansen, L., Pruett, E.D., Osnes, J.B., Giere, F.A. (1970). Blood glucose and plasma insulin in response to maximal exercise and glucose infusion. J Appl Physiol, 29 (1), 13-1.

Hortobagyi, T., Denhan, T. (1989). Variability in creatine kinase: methodological, exercise and clinically related factors. Int $J$ Sports Med, 10, 69-80.

Hübner-Woźniak, E., Kosmol, A., Lutoslawska, G., Bem, E.Z. (2004). Anaerobic performance of arms and legs in male and female free style wrestlers. Journal of Science and Medicine in Sport, 7, 473-480.

Hübner-Woźniak, E., Lutoslawska, G., Kosmol, A., Zuziak, S. (2006). The effect of training experience on arm muscle anaerobic performance in wrestlers. Human Movement, 7, 147-152.

Hughes, L., Paton, B., Rosenblatt, B., Gissane, C., Patterson, S.D. (2017). Blood flow restriction training in clinical musculoskeletal rehabilitation: a systematic review and meta-analysis. J Sports Med, 51, 1003-1011.

Hunter, S.K., Critchlow, A., Shin, I.S., Enoka, R.M. (2004). Fatigability of the elbow flexor muscles for a sustained submaximal contraction is similar in men and women matched for strength. J Appl Physiol, 96, 195-202.

Jemni, M., Sands, W., Friemel, F., Delamarche, P. (2003). Effect of Active and Passive Recovery on Blood Lactate and Performance During Simulated Competition in High Level Gymnasts. Can. J. Appl. Physiol, 28 (2), 240-256.

Jones, M. (2016). Investigation of Sequential Intermittent Pneumatic Compression Effect on Run Performance. UNLV Theses Dissertations, Professional Papers, and Capstones. 2688. 
Karninčić, H., Gamulin, T., Nurkić, M. (2013). Lactate and Glucose Dynamics During A Wrestling Match - Differences Between Boys, Cadets and Juniors. Physical Education and Sport, 11 (2), 125-133.

Karninčić, H., Tocilj, Z., Uljević, O., Erceg, M. (2009). Lactate profile during Greco-Roman wrestling match. Journal of Sports Science and Medicine, 8, 17-19.

Kass, L., Carpenter, R. (2009). The Effect of Sampling Time on Blood Lactate Concentration ([Bla]). In: Trained Rowers. Int J Sports Physiol Perform, 4 (2), 218-28.

Khayat, Z.A., Patel, N., Klip, A. (2002). Exercise and insulin-stimulated muscle glucose transport: distinct mechanisms of regulation. Can J App Physiol, 27 (2), 129-51.

Koch, A.J., Pereira, R., Machado, M. (2014). The creatine kinase response to resistance exercise. J Musculoskelet Neuronal Interact, 14 (1), 68-77.

Kraemer, W.J., Flanagan, S.D., Comstock, B.A., Fragala, M.S., Earp, J.E., Dunn-Lewis, C. (2010). Effects of a whole-body compression garment on markers of recovery after a heavy resistance workout in men and women. J Strength Cond Res, 24 (3), 804-814.

Kraemer, W.J., Fry, A.C., Rubin, M.R., Triplett-McBride, T., Gordon, S.E., Koziris, L.P., Lynch, J.M., Volek, J.S., Meuffels, D.E., Newton, R.U., Fleck, S.J. (2001). Physiological and performance responses to tournament wrestling. Medicine and Science in Sports and Exercise, 33, 1367-1378.

Kraus, A., Pasha, E., Machin, D., Alkatan, M., Kloner, R., Tanaka, H. (2015). Bilateral Upper Limb Remote Ischemic Preconditioning Improves Anaerobic Power. Sports Medicine Journal, 9, 1-6.

Labropoulos, N., Cunningham, J., Kang, S.S., Mansour, M.A., Baker, W.H. (2010). Optimising the performance of intermittent pneumatic compression devices. European Journal of Vascular \& Endovascular Surgery, 19 (6), 593-597.

Lévénez, M., Kotzamanidis, C., Carpentier, A., Duchateau, J. (2005). Spinal reflexes and co activation of ankle muscles during a submaximal fatiguing contraction. J Appl Physiol, 98, 120-131.

Locke, S., Osborne, M., O'rouke, P. (2009). Persistent fatigue in young athletes: measuring the clinical course and identifying variables affecting clinical recovery. Scand J Med Sci Sports, 21 (1), 90-97.

Lopes, T., Sabino, J., Ferreira, T., Succi, J., Silva, A., Silba, B. (2018). Effect of Ischemic Preconditioning on the Recovery of Cardiac Autonomic Control from Repeated Sprint Exercise. Frontiers in Physiology, 9, 1465.

Mahdi, K. (2007). Comparing three types of recovery programs on removal of lactate after an intensive exercise. 12th Annual Congress European College of Sports Science, July 11-14, Jyvaskyla - Finland.

Marliss, E.B., Vranic, M. (2002). Intense exercise has unique effects on both insulin release and its roles in gluco regulation: implications for diabetes. Diabetes, 51, suppl 1, 21 (1), 1-12.

Marshall, W. (2012). Glucose (Blood, serum, plasma). Association for Clinical Biochemistry, 1-7.

McNeil, C.J., Allen, M.D., Olympico, E., Shoemaker, J.K., Rice, C.L. (2015). Blood flow and muscle oxygenation during low, moderate, and maximal sustained isometric contractions. Am J Physiol Regul Integr Comp Physiol, 309, 475-481.

McNeil, C.J., Murray, B.J., Rice, C.L. (2006). Differential changes in muscle oxygenation between voluntary and stimulated isometric fatigue of human dorsiflexors. J Appl Physiol, 100, 890-895.

Meeusen, R., Duclos, M., Foster, C., Fry, A., Gleeson, M., Nieman, D. (2013). Prevention, diagnosis, and treatment of the overtraining syndrome: joint consensus statement of the European College of Sport Science and the American College of Sports Medicine. Med Sci Sports Exerc, 45, 186-205.

Mikines, K.J., Sonne, B., Farrel, P.A., Tronier, B., Galbo, H. (1988). Effect of physical exercise on sensitivity and responsiveness to insulin in humans. Am. J. Physiol, 254, E248-E259.

Miller, B.F., Fattor, J.A., Jacobs, K.A., Horning, M.A., Navazio, F., Lindinger, M.I., Brooks, G.A. (2002). Lactate and glucose interactions during rest and exercise in men: effect of exogenous lactate infusion. J Physiol, 544 (3), 963-975.

Papassotiriou, I., Nifli, A. (2018). Assessing performance in pre-season wrestling athletes using biomarkers. Biochem Med, 28 (2).

Perrone, R.D., Madias, N.E., Levey, A.S. (1992). Serum creatinine as an index of renal function: new insights into old concepts. Clin Chem, 38, 1933-53.

Pruscino, C. (2013). Effects of Compression Garments on Recovery from Intermittent Exercise. Master Thesis, the University of Melbourne.

Rehrer, N.J., Brouns, F., Beckers, E.J. (1992). Physiological changes and gastro-intestinal symptoms as a result of ultra-endurance running. Eur J Appl Physiol Occup Physiol, 64 (1), 1-8.

Richter, E.A., Derave, W., Wojtaszewski, J.F. (2001). Glucose, exercise, and insulin: emerging concepts. J Physiol, 535 (2), 313-22. 
Riksen, N.P., Smits, P., Rongen, G.A. (2004). Ischaemic preconditioning: from molecular characterisation to clinical application - part 1. Neth J Med, 62 (10), 353-63.

Robergs, R.A., Ghiasvand, F., Parker, D. (2004). Biochemistry of exercise-induced metabolic acidosis. Am J Physiol Regul Integr Comp Physiol, 287 (3), R502-516.

San Millán, I., Bing, K., Brill, C., C Hill, J., Miller, L. (2013). Randomized controlled trial of Micro-Mobile compression on lactate clearance and subsequent exercise performance in elite male cyclists. Journal of Sports Medicine, 4, 221-227.

Sharma, L., Verma, S. (2017). Effect of recovery modalities on blood lactate clearance. Saudi Journal of Sports Medicine, 17 (2).

Slysz, J., Stultz, J., Burr, J.F. (2016). The efficacy of blood flow restricted exercise: A systematic review \& meta-analysis. J Sci Med Sport, 19 (8), 669-675.

Soman, V.R., Koivisto, V.A., Deibert, D., Felig, P., DeFronzo, R.A. (1997). Increased insulin sensitivity and insulin binding to monocytes after physical training. N. Engl. J. Med, 301, 1200-1204.

Sybil, M. (2018). Biochemical changes in cluster analysis indicators because of special tests of freestyle wrestlers of a lactate and lactate types of power supply. Journal of Physical Education and Sport, 18 (1), 235-238.

Tapuria, N., Kumar, Y., Habib, M.M., Abu Amara, M., Seifalian A.M., Davidson, B.R. (2008). Remote ischemic preconditioning: a novel protective method from ischemia reperfusion injury - a review. J. Surg. Res, 150, 304-330.

Thorpe, R., Atkinson, G., Drust, B., Gregson, W. (2017). Monitoring fatigue status in elite team sport athletes: Implications for practice. Int J Sports Physiol Perform, 12 (2), S227-S234.

Tschakovsky, M.E., Rogers, A.M., Pyke, K.E., Saunders, N.R., Glenn, N., Lee, S.J., Dwyer, E.M. (2004). Immediate exercise hyperemia in humans is contraction intensity dependent: evidence for rapid vasodilation. Journal of Applied Physiology, 96 (2), 639-644.

Utter, A.C., O'Bryant, H.S., Haff, G.G., Trone, G.A. (2002). Physiological profile of an elite freestyle wrestler preparing for a competition: A case study. Journal of Strength and Condition Research, 16, 308-315.

Waller, T., Caine, M., Morris R. (2006). Intermittent Pneumatic Compression Technology for Sports Recovery. Engineering of Sport, 6, 391-396.

Winke, M., Williamson, S.H. (2018). Comparison of a Pneumatic Compression Device to a Compression Garment During Recovery from DOMS. Int J Exerc Sci, 11 (3), 375-383.

Cite this anticle as: Ghoraba, M.S., Ghazy, M.F. (2019). Effect of Compression Modalities for Recovery on Wrestlers' Biomarkers in One Day Tournament. Central European Journal of Sport Sciences and Medicine, 4 (28), 39-51. DOI: 10.18276/cej.2019.4-04. 